\title{
Outcome of Microscopic Incomplete Resection (R1) of Colorectal Liver Metastases in the Era of Neoadjuvant Chemotherapy
}

\author{
Ninos Ayez, MD' ${ }^{1}$, Zarina S. Lalmahomed, $\mathrm{MD}^{2}$, Alexander M. M. Eggermont, $\mathrm{MD}, \mathrm{PhD}^{3}$, Jan N. M. Ijzermans, \\ $\mathrm{MD}, \mathrm{PhD}^{2}$, Jeroen de Jonge, $\mathrm{MD}, \mathrm{PhD}^{1,2}$, Kees van Montfort, $\mathrm{PhD}^{4}$, and Cornelis Verhoef, $\mathrm{MD}, \mathrm{PhD}^{1}$ \\ ${ }^{1}$ Division of Surgical Oncology, Erasmus MC, Daniel den Hoed Cancer Center, Rotterdam, The Netherlands; ${ }^{2}$ Division of \\ Transplantation and Hepatobiliary Surgery, Erasmus MC, Rotterdam, The Netherlands; ${ }^{3}$ Institut de cancérologie Gustav \\ Roussy, Villejuif, France; ${ }^{4}$ Division of Biostatistics, Erasmus MC, Daniel den Hoed Cancer Center, Rotterdam, The \\ Netherlands
}

\begin{abstract}
Background. Data from patients with colorectal liver metastases (CRLM) who received neoadjuvant chemotherapy before resection were reviewed and evaluated to see whether neoadjuvant chemotherapy influences the predictive outcome of $\mathrm{R} 1$ resections (margin is $0 \mathrm{~mm}$ ) in patients with CRLM.

Methods. Between January 2000 and December 2008, all consecutive patients undergoing liver resection for CRLM were analyzed. Patients were divided into those who did and did not receive neoadjuvant chemotherapy. The outcome after R0 (tumor-free margin $>0 \mathrm{~mm}$ ) and R1 (tumorfree margin $0 \mathrm{~mm}$ ) resection was compared.

Results. A total of 264 were eligible for analysis. Median follow-up was 34 months. Patients without chemotherapy showed a significant difference in median disease-free survival (DFS) after R0 or R1 resection: 17 [95\% confidence interval (CI) 10-24] months versus 8 (95\% CI 4-12) months $(P<0.001)$, whereas in patients with neoadjuvant chemotherapy the difference in DFS between R0 and R1 resection was not significant: 18 (95\% CI 10-26) months versus 9 (95\% CI $0-20)$ months $(P=0.303)$. Patients without chemotherapy showed a significant difference in median overall survival (OS) after R0 or R1 resection: 53 (95\% CI 40-66) months versus 30 (95\% CI 13-47) months $(P<0.001)$. In patients with neoadjuvant chemotherapy,
\end{abstract}

(C) The Author(s) 2011. This article is published with open access at Springerlink.com

First Received: 19 June 2011;

Published Online: 18 October 2011

C. Verhoef, MD, $\mathrm{PhD}$

e-mail: c.verhoef@erasmusmc.nl the median OS showed no significant difference: 65 (95\% CI 39-92) months for the R0 group versus the R1 group, in whom the median OS was not reached $(P=0.645)$.

Conclusions. In patients treated with neoadjuvant chemotherapy, R1 resection was of no predictive value for DFS and OS.

Without treatment, patients with colorectal liver metastases (CRLM) have a median survival of 5-8 months. ${ }^{1-3}$ Unfortunately, only approximately $20-30 \%$ of patients with CRLM have resectable disease at the time of diagnosis. ${ }^{4,5}$ After resection, 5-year survival rates of $21-48 \%$ have been reported. ${ }^{6-8}$ Nowadays, chemotherapy regimens are highly effective and can result in response rates of $50-80 \%$ and seem to convert $10-30 \%$ of formerly irresectable CRLM to a resectable size or situation. . $^{6,9,10}$

Several studies have described risk factors for the outcome of patients with CRLM. ${ }^{8,11-17}$ Surgical margin status has been described as the major determinant of survival after resection, with $\mathrm{R} 1$ resections doing worse compared to $\mathrm{R} 0$ resections. However, the impact of the several proposed cutoff points regarding R0 resections remains controversial.

Some older studies proposed a surgical margin of $\leq 1 \mathrm{~cm}$ as a contraindication for resection. ${ }^{16,18-20}$ Others demonstrated that a resection margin $\leq 1 \mathrm{~cm}$ is not a contraindication, providing a radical resection (minimal margin of $1 \mathrm{~mm}$ ) is performed. ${ }^{21-25}$

However, these studies did not evaluate the specific group of patients who received neoadjuvant chemotherapy before resection of CRLM. Therefore, the present study analyzes whether a resection margin of $0 \mathrm{~mm}$ is sufficient in the era of effective neoadjuvant chemotherapy. 


\section{METHODS}

Between January 2000 and December 2008, all consecutive patients who underwent liver resection for CRLM were analyzed. Patients were eligible for this study if they fulfilled the following criteria: macroscopic complete resection; clear description of surgical margin status by the pathologist for each metastasis; no evidence of concomitant extrahepatic disease; no simultaneous use of local treatment modalities (radiofrequency ablation and/or cryotherapy). ${ }^{26}$

All patients underwent preoperative screening to assess the extent of the metastases by clinical examination and chest and abdominal imaging (ultrasound, computed tomography $[\mathrm{CT}]$, magnetic resonance imaging). In our institute, positron emission tomography is not routinely used. Also, serum tumor marker levels (carcinoembryonic antigen, CEA) and colonoscopy were performed preoperatively.

\section{Chemotherapy}

We are a tertiary referral hospital, and we do not administer perioperative chemotherapy as a standard treatment protocol for patients with CRLM. Most patients had already received neoadjuvant chemotherapy in the referring hospital. In our clinic, patients received neoadjuvant chemotherapy in cases of initially difficult/ unresectable liver metastases (poor location) or multiple synchronous metastases $\geq 4$. Patients received a combination of 5-fluorouracil/capecitabine and oxaliplatin or irinotecan, with or without bevacizumab. The response to neoadjuvant chemotherapy was assessed after two or three cycles by CT scan and CEA levels. Further treatment was discussed according to the tumor response and extent of the disease. When the liver metastases were resectable, a laparotomy was planned more than 3 weeks after the last course of systemic neoadjuvant chemotherapy. Bevacizumab had to be excluded from the last course of chemotherapy to ensure an interval of at least 6 weeks. None of the patients received adjuvant chemotherapy as standard therapy after liver resection. The time period from 2000 was chosen because of the introduction of more effective chemotherapy and also because after 2000 the definition of resectability was not changed in our clinic.

\section{Liver Resection}

Hepatic parenchymal resection was performed with an ultrasonic surgical aspirator (Cavitron; Valleylab, Boulder, $\mathrm{CO}$ ) and a monopolar coagulator. R0 was defined by the absence of microscopic tumor invasion of the resection margin (tumor-free margin $>0 \mathrm{~mm}$ ), and R1 was defined by the presence or microscopic tumor invasion of the resection margin (tumor-free margin $0 \mathrm{~mm}$ ).
Follow-up

Postoperative follow-up consisted of clinical examination and measurement of CEA every 3 months. Abdominal imaging (ultrasound, CT of thorax and abdomen) was performed at 3, 6, 9, and 12 months in the first year; every 6 months the second year; and once a year thereafter. If disease recurred, a decision on whether to initiate chemotherapy treatment again was made by the multidisciplinary team.

\section{Outcome}

Overall survival (OS) was defined as the interval in months between resection of CRLM and death, or the date of last follow-up. Disease-free survival (DFS) was defined as the interval in months between resection of CRLM and recurrence, death without recurrence, or date of last followup without recurrence.

\section{Statistical Analysis}

Descriptive values are expressed as median (range). Comparison between categorical variables was determined by the chi-square test or Fisher's exact test as appropriate. Survival analysis was performed by the Kaplan-Meier method. Comparison between survival curves was made by $\log$ rank tests. Univariate analysis was performed by Cox regression analysis. For the multivariate analysis, only parameters with a $P$ value of $<0.25$ in the univariate model were entered in the Cox regression model. Backward elimination was applied. Variables were included if $P$ values were $\leq 0.05$ and were removed if $P$ values were $>0.10$. SPSS statistical software, version 17.0 (SPSS, Chicago, IL), was used for statistical analysis; a $P$ value of $\leq 0.05$ was considered statistically significant.

\section{RESULTS}

Between January 2000 and December 2008, a total of 352 patients underwent liver resection for CRLM (Fig. 1). Of these, 81 patients $(23 \%)$ were excluded because of extrahepatic disease, concomitant local treatment, and/or macroscopic incomplete liver resection. Seven patients (2\%) had unknown margin status. Finally, 264 patients (75\%) were eligible for analysis. One patient was lost to follow-up at 21 months. Neoadjuvant chemotherapy was provided to 92 (35\%) of 264 patients. Thirty-eight patients (41\%) received concomitant bevacizumab.

Patient characteristics are listed in Tables 1 and 2. An $\mathrm{R} 1$ resection was found in 33 patients (13\%). R1 resections in patients without chemotherapy and with chemotherapy were comparable: 13 vs. $12 \%(P=0.845)$. 


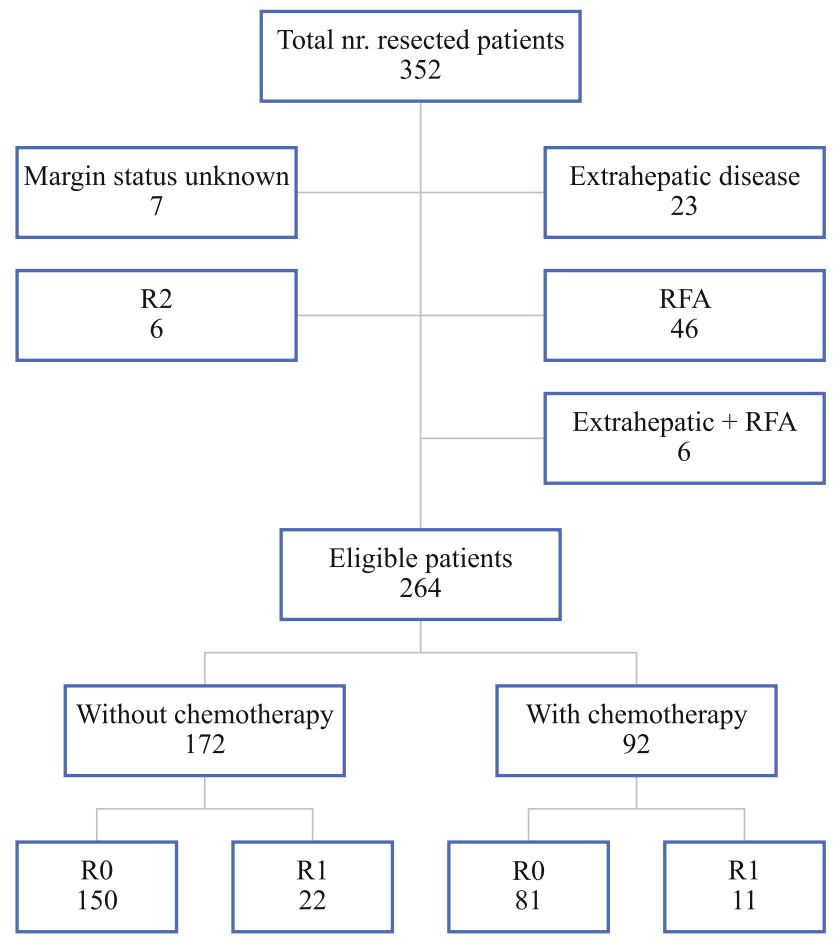

FIG. 1 Flowchart of the study

TABLE 1 Characteristics of patients by chemotherapy treatment

Data are presented as $n(\%)$ unless otherwise indicated
The median follow-up was 34 (range 0-121) months. Five patients $(1.9 \%)$ died postoperatively, 3 due to liver and kidney failure and 2 due to aspiration followed by sepsis.

The median DFS was 14 [95\% confidence interval (CI) 10-18] months for patients without chemotherapy, and for patients with neoadjuvant chemotherapy it was 16 (95\% CI 8-24) months $(P=0.962)$. In patients without chemotherapy, the median DFS showed a significant difference between the R0 and R1 resection: 17 (95\% CI 10-24) months versus 8 (95\% CI $4-12)$ months $(P<0.001)$. In patients with neoadjuvant chemotherapy, the median DFS showed no significant difference between the R0 and R1 resection: 18 (95\% CI 10-26) months versus $9(95 \% \mathrm{CI}$ 0-20) months ( $P=0.303)$ (Fig. 2).

During follow-up, 171 patients $(65 \%)$ developed recurrence. Local treatment was performed in 74 patients $(43 \%)$ (surgery, radiofrequency ablation, stereotactic radiotherapy), 80 patients $(47 \%)$ received palliative chemotherapy, and 17 patients $(10 \%)$ did not receive chemotherapy or local treatment. There was no difference in treatment of the recurrence between patients who were treated with or without neoadjuvant chemotherapy $(P=0.253)$.

\begin{tabular}{|c|c|c|c|c|c|}
\hline \multirow[t]{2}{*}{ treatment } & \multirow[b]{2}{*}{ Male sex } & Value & \multicolumn{2}{|l|}{ Value } & \multirow{2}{*}{$\begin{array}{l}\text { Value } \\
169(64 \%)\end{array}$} \\
\hline & & $107(62 \%)$ & $62(67 \%)$ & 0.403 & \\
\hline & Age & $65(30-86)$ & $62(36-84)$ & 0.714 & $64(30-86)$ \\
\hline & \multicolumn{5}{|l|}{ Primary tumor } \\
\hline & Rectal cancer & $84(49 \%)$ & $45(49 \%)$ & 0.991 & $129(49 \%)$ \\
\hline & \multicolumn{5}{|l|}{$\mathrm{T}$ stage } \\
\hline & $\mathrm{T} 3$ & $124(72 \%)$ & $66(72 \%)$ & & $190(72 \%)$ \\
\hline & $\mathrm{T} 4$ & $12(7 \%)$ & $8(9 \%)$ & & $20(8 \%)$ \\
\hline & Missing data & - & $2(2 \%)$ & & $2(1 \%)$ \\
\hline & Positive lymph node & $97(56 \%)$ & $56(61 \%)$ & 0.364 & $153(58 \%)$ \\
\hline & Missing data & - & $2(2 \%)$ & & $2(1 \%)$ \\
\hline & \multicolumn{5}{|l|}{ Liver metastases } \\
\hline & Synchronous & $52(30 \%)$ & $67(73 \%)$ & $<0.001$ & $119(45 \%)$ \\
\hline & \multicolumn{5}{|l|}{ Diameter (cm) } \\
\hline & Median (range) & $3.3(0.9-15)$ & $3.5(0.5-18)$ & 0.068 & $3.4(0.5-18)$ \\
\hline & Missing data & $2(1 \%)$ & $2(2 \%)$ & & $4(2 \%)$ \\
\hline & \multicolumn{3}{|l|}{ No. of metastases } & $<0.001$ & \\
\hline & Median (range) & $1(1-8)$ & $2.0(1-8)$ & & $2(1-8)$ \\
\hline & Missing data & $1(1 \%)$ & - & & $1(0.5 \%)$ \\
\hline & Bilobar & $43(25 \%)$ & $36(39 \%)$ & 0.017 & $79(30 \%)$ \\
\hline & \multicolumn{3}{|l|}{ Resection type } & 0.544 & \\
\hline & Anatomical & $78(45 \%)$ & $41(45 \%)$ & & $119(45 \%)$ \\
\hline & Nonanatomical & $69(40 \%)$ & $33(36 \%)$ & & $102(39 \%)$ \\
\hline & Combined & $25(15 \%)$ & $18(20 \%)$ & & $43(16 \%)$ \\
\hline $\begin{array}{l}\text { Data are presented as } n(\%) \\
\text { unless otherwise indicated }\end{array}$ & $\mathrm{R} 1$ resection & $22(13 \%)$ & $11(12 \%)$ & 0.845 & $33(13 \%)$ \\
\hline
\end{tabular}


TABLE 2 Characteristics of patients by resection margin
Data are presented as $n(\%)$ unless otherwise indicated

\begin{tabular}{|c|c|c|c|c|}
\hline Characteristic & $\mathrm{R} 0(n=231)$ & $\mathrm{R} 1(n=33)$ & $P$ value & $\begin{array}{l}\text { All patients } \\
(n=264)\end{array}$ \\
\hline Male & $152(66 \%)$ & $17(52 \%)$ & 0.123 & $169(64 \%)$ \\
\hline Age, median (range) & $64(31-86)$ & $62(30-77)$ & 0.499 & $64(30-86)$ \\
\hline \multicolumn{5}{|l|}{ Primary tumor } \\
\hline Rectal cancer & $117(51 \%)$ & $12(36 \%)$ & 0.139 & $129(49 \%)$ \\
\hline $\mathrm{T}$ stage & & & 0.682 & \\
\hline T3 & $163(71 \%)$ & $27(82 \%)$ & & $190(72 \%)$ \\
\hline $\mathrm{T} 4$ & $18(8 \%)$ & $2(6 \%)$ & & $20(8 \%)$ \\
\hline Missing data & $2(1 \%)$ & - & & $2(1 \%)$ \\
\hline Positive lymph node & $127(55 \%)$ & $26(79 \%)$ & 0.011 & $153(58 \%)$ \\
\hline Missing data & $2(1 \%)$ & & & $2(1 \%)$ \\
\hline \multicolumn{5}{|l|}{ Liver metastases } \\
\hline Synchronous & $106(46 \%)$ & $13(39 \%)$ & 0.483 & $119(45 \%)$ \\
\hline Diameter (cm) & & & 0.048 & \\
\hline Median (range) & $3.2(0.5-18)$ & $3.9(1.6-7.0)$ & & $3.4(0.5-18)$ \\
\hline Missing data & $4(2 \%)$ & - & & $4(2 \%)$ \\
\hline No. metastases & & & 0.173 & \\
\hline Median & $1(1-8)$ & $3.0(1-8)$ & & $2(1-8)$ \\
\hline Missing data & $1(1 \%)$ & - & & $1(0.5 \%)$ \\
\hline Bilobar & $61(26 \%)$ & $18(55 \%)$ & 0.001 & $79(30 \%)$ \\
\hline Resection type & & & 0.513 & \\
\hline Anatomical & $107(46 \%)$ & $12(37 \%)$ & & $119(45 \%)$ \\
\hline Nonanatomical & $88(38 \%)$ & $14(42 \%)$ & & $102(39 \%)$ \\
\hline Combined & $36(16 \%)$ & $7(21 \%)$ & & $43(16 \%)$ \\
\hline \multicolumn{5}{|l|}{ Chemotherapy } \\
\hline Neoadjuvant chemotherapy & $81(35 \%)$ & $11(33 \%)$ & 0.845 & $92(35 \%)$ \\
\hline
\end{tabular}

In total, 54 patients (20\%) had intrahepatic recurrence only, 87 patients $(33 \%)$ had extrahepatic recurrence only, and 30 patients $(11 \%)$ had intrahepatic and extrahepatic recurrence. There was no difference in recurrences located at the surgical liver margins between $\mathrm{R} 0$ and $\mathrm{R} 1$ resection in patients with and without chemotherapy $(P=0.853$ and $P=0.839$, respectively).

The median OS was 48 (95\% CI 39-57) months for patients without chemotherapy and 65 months (95\% CI not reached) for patients with neoadjuvant chemotherapy $(P=0.103)$. In patients without chemotherapy, the median OS showed a significant difference between R0 and R1 resection: 53 (95\% CI 40-66) months versus 30 (95\% CI 13-47) months $(P<0.001)$. In patients with neoadjuvant chemotherapy, the median OS showed no significant difference between the R0 resection, 65 (95\% CI 39-92) months, and the R1 resection, where the median OS was not reached $(P=0.645)$ (Fig. 2).

A similar trend was found if a tumor-free margins of $0-2 \mathrm{~mm}$ versus $>2 \mathrm{~mm}$ and $0-5 \mathrm{~mm}$ versus $>5 \mathrm{~mm}$ was chosen. The 5-year OS was $35 \%$ for patients without neoadjuvant chemotherapy who had R0 resection with $\leq 2 \mathrm{~mm}$ from the resection margin $(n=42)$, whereas for patients who had a $\mathrm{R} 0$ resection with $>2 \mathrm{~mm}$ from the resection margin $(n=100)$, the 5 -year OS was $51 \%$ $(P=0.04)$. In patients with neoadjuvant chemotherapy, this phenomenon could not be demonstrated: $65 \%(n=28)$ versus $45 \%(n=48)(P=0.564)$. When comparing $0-5$ mm versus $>5 \mathrm{~mm}$, the 5 -year OS was 55 vs. $36 \%$ in patients without chemotherapy $(P=0.062)$ and 44 vs. $63 \%$ in patients with chemotherapy $(P=0.361)$.

Predictive factors in univariate and multivariate analysis are listed in Table 3. In the total study population of 264 patients, multivariate analysis showed four factors predictive for survival: $\mathrm{T}$ stage primary tumor [hazard ratio $(\mathrm{HR})=2.0$ [95\% CI 1.1-3.5]; $P=0.016]$. Positive lymph nodes in primary tumor $(\mathrm{HR}=1.5$ [95\% CI 1.0-2.2]; $P=0.039)$, number of metastases $(\geq 4)(\mathrm{HR}=1.8[95 \%$ CI 1.1-2.9]; $P=0.028$ ) and neoadjuvant chemotherapy $(\mathrm{HR}=0.62[95 \%$ CI $0.4-0.9] ; P=0.027$ ).

\section{DISCUSSION}

This study reviews patients with CRLM who received neoadjuvant chemotherapy before resection and evaluates 
FIG. 2 R0 versus R1 resection in patients without and with chemotherapy for DFS and OS
DFS without chemo

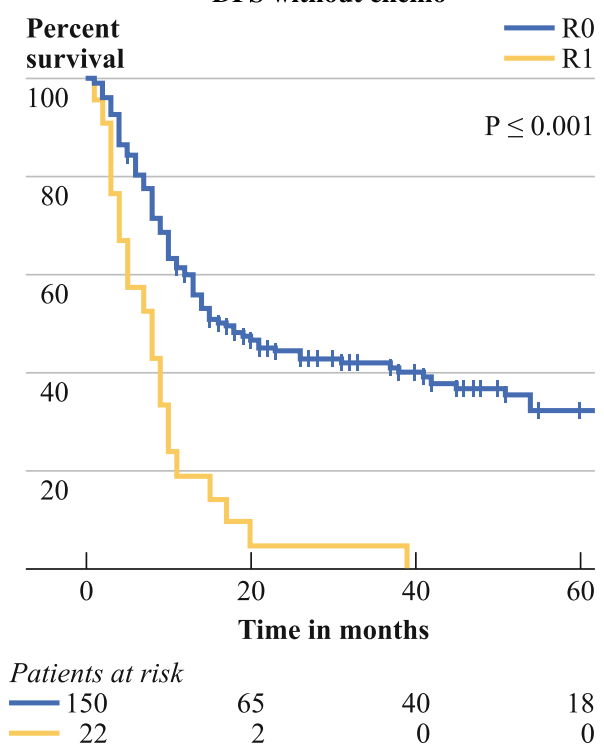

OS without chemo

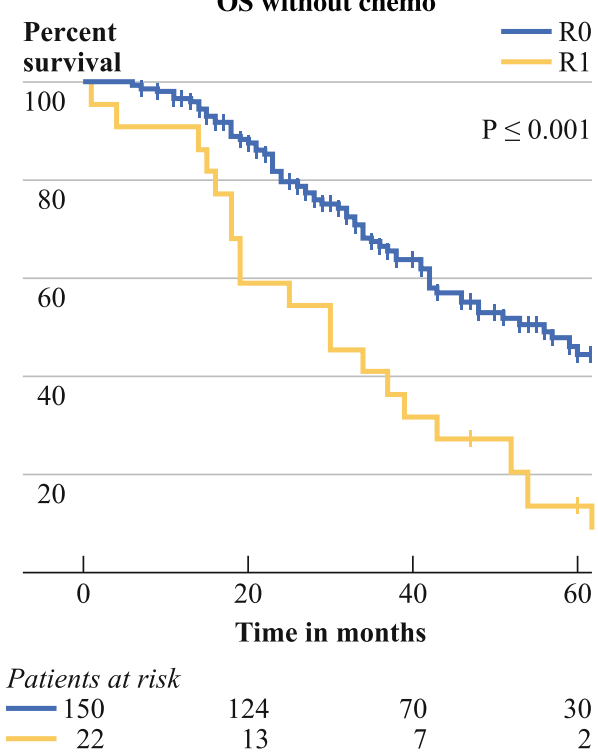

DFS with chemo

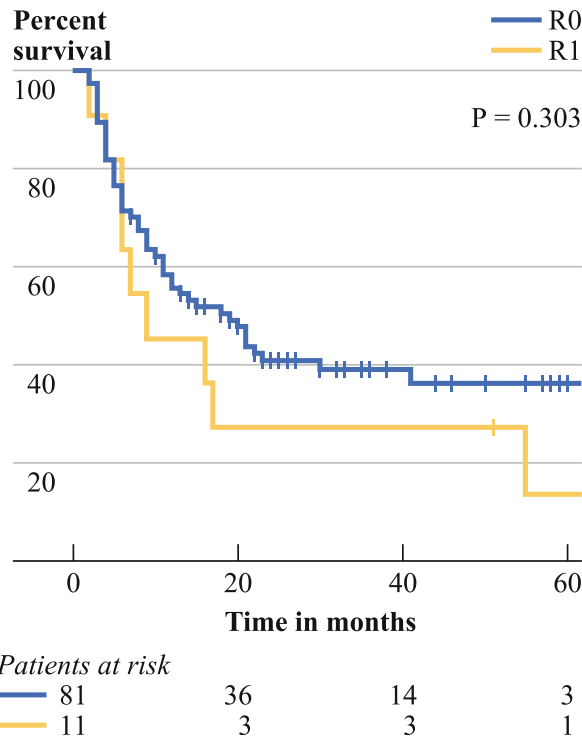

OS with chemo

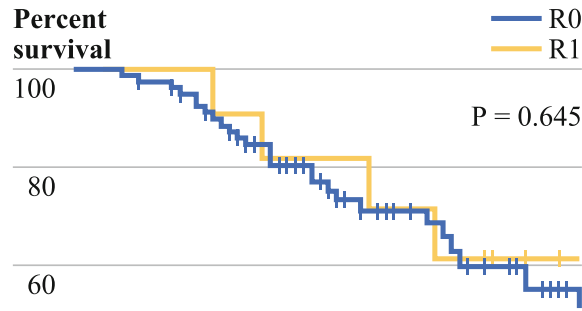

40

20

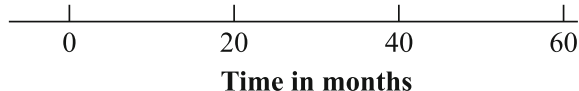

Patients at risk whether neoadjuvant chemotherapy affects the predictive value of resection margins. In patients with neoadjuvant chemotherapy, those with a $\mathrm{R} 1$ resection did not fare worse than those with a $\mathrm{R} 0$ resection $(P=0.303$ and $P=0.645$, respectively). In our series, we found $13 \% \mathrm{R} 1$ resections, which is comparable to data in found at other centers $(5-46 \%) .^{11,18,21,26-29}$

Earlier studies found that a clear resection margin of $1 \mathrm{~cm}$ was found to be a good predictor of survival. ${ }^{30,31}$ Others have confirmed these results. ${ }^{16,18-20}$ With new insights in CRLM surgery in the last decade, some report that the $1-\mathrm{cm}$ rule is outdated and should not preclude resection, provided a complete resection is possible. ${ }^{21-25,32}$ De Haas et al. even reported that they did not find any difference in DFS and OS between R0 and R1 resections $\left(P=0.12\right.$ and $P=0.27$, respectively). ${ }^{26}$ In their study, $74 \%$ of the patients received neoadjuvant chemotherapy and $26 \%$ did not receive neoadjuvant chemotherapy; however, they did not describe these two groups separately. In $83 \%$ of their patients, surgery was followed by adjuvant chemotherapy.

The present study demonstrates comparable results when we divide the cohort into patients who did and did not receive neoadjuvant chemotherapy. However, one major difference is that none of our patients received adjuvant chemotherapy after CRLM surgery. As yet, to our knowledge, there are no randomized data to support adjuvant chemotherapy alone after liver resection. The liver 
TABLE 3 Data on univariate and multivariate analysis

\begin{tabular}{|c|c|c|c|c|c|c|}
\hline \multirow[t]{2}{*}{ Characteristic } & \multicolumn{3}{|c|}{ Without chemotherapy } & \multicolumn{3}{|c|}{ With chemotherapy } \\
\hline & $\begin{array}{l}\text { Median survival } \\
(95 \% \mathrm{CI})\end{array}$ & $\begin{array}{l}\text { Univariate } \mathrm{HR} \\
(95 \% \mathrm{CI}), P \text { value }\end{array}$ & $\begin{array}{l}\text { Multivariate } \\
\text { HR }(95 \% \text { CI })\end{array}$ & $\begin{array}{l}\text { Median survival } \\
(95 \% \mathrm{CI})\end{array}$ & $\begin{array}{l}\text { Univariate } \mathrm{HR} \\
(95 \% \mathrm{CI}), P \text { value }\end{array}$ & $\begin{array}{l}\text { Multivariate } \\
\text { HR }(95 \% \text { CI) }\end{array}$ \\
\hline \multicolumn{7}{|c|}{ Disease-free survival } \\
\hline \multicolumn{7}{|l|}{ Sex } \\
\hline Male & $14(10-18)$ & 0.95 (0.65-1.39), 0.789 & NS & $17(6-28)$ & 1.03 (0.60-1.77), 0.914 & NS \\
\hline Female & $13(7-19)$ & & & $14(3-25)$ & & \\
\hline \multicolumn{7}{|l|}{ Age } \\
\hline$<60$ years & $14(4-24)$ & 1.09 (0.72-1.64), 0.692 & NS & $11(6-16)$ & $0.87(0.52-1.48), 0.617$ & NS \\
\hline$\geq 60$ years & $14(10-18)$ & & & $21(13-29)$ & & \\
\hline \multicolumn{7}{|l|}{ Primary tumor } \\
\hline Rectum & $13(10-16)$ & $0.86(0.60-1.25), 0.440$ & NS & $17(3-31)$ & 1.23 (0.73-2.08), 0.440 & NS \\
\hline Colon & $15(9-21)$ & & & $15(4-26)$ & & \\
\hline \multicolumn{7}{|c|}{$\mathrm{T}$ stage primary tumor } \\
\hline $\mathrm{T} 1-3$ & $15(11-19)$ & $2.00(1.07-3.73), 0.029$ & $2.52(1.33-4.76)$ & $18(11-25)$ & 2.56 (1.16-5.67), 0.021 & $2.4(1.08-5.34)$ \\
\hline $\mathrm{T} 4$ & $6(0-14)$ & & 0.004 & $4(1-7)$ & & 0.032 \\
\hline \multicolumn{7}{|l|}{ Lymph node } \\
\hline Negative & $26(0-57)$ & $1.70(1.4-2.5), 0.009$ & $1.53(1.02-2.29)$ & $16(0-36)$ & 1.29 (0.74-2.24), 0.371 & $2.35(1.28-4.31)$ \\
\hline Positive & $10(6-14)$ & & 0.042 & $17(8-26)$ & & 0.006 \\
\hline \multicolumn{7}{|l|}{ Hepatic metastases } \\
\hline \multicolumn{7}{|l|}{ Time diagnosis } \\
\hline Metachronous & $15(8-22)$ & $1.30(0.9-1.9), 0.174$ & NS & $19(8-30)$ & 1.10 (0.61-1.98), 0.751 & NS \\
\hline Synchronous & $13(8-18)$ & & & $14(7-21)$ & & \\
\hline \multicolumn{7}{|l|}{ No. of metastases } \\
\hline$\leq 3$ & $26(0-57)$ & $2.00(1.1-3.5), 0.024$ & NS & $21(9-33)$ & 2.47 (1.37-4.44), 0.003 & NS \\
\hline$\geq 4$ & $10(6-14)$ & & & $6(5-7)$ & & \\
\hline \multicolumn{7}{|c|}{ Largest metastasis size } \\
\hline$<4$ & $16(10-22)$ & $1.10(0.75-1.62), 0.637$ & NS & $12(6-18)$ & $0.74(0.40-1.37), 0.338$ & NS \\
\hline$\geq 4$ & $11(8-140$ & & & $23(0-64)$ & & \\
\hline \multicolumn{7}{|c|}{ Tumor distribution } \\
\hline Unilobar & $16(8-24)$ & $1.41(0.94-2.10), 0.093$ & NS & $21(0-44)$ & $1.80(1.07-3.03), 0.027$ & NS \\
\hline Bilobar & $10(8-12)$ & & & $11(7-15)$ & & \\
\hline \multicolumn{7}{|l|}{ CEA level } \\
\hline$<50$ & $16(11-21)$ & 1.39 (0.91-2.11), 0.129 & NS & $15(7-23)$ & $1.06(0.48-2.35), 0.880$ & NS \\
\hline$\geq 50$ & $8(4-12)$ & & & $21(0-50)$ & & \\
\hline \multicolumn{7}{|l|}{ Resection margin } \\
\hline R0 & $17(10-24)$ & $3.08(1.90-5.01),<0.001$ & $2.86(1.70-4.78)$ & $18(10-26)$ & 1.44 (0.71-2.94), 0.315 & NS \\
\hline $\mathrm{R} 1$ & $8(4-12)$ & & $<0.001$ & $9(0-20)$ & & \\
\hline \multicolumn{7}{|l|}{ Overall survival } \\
\hline \multicolumn{7}{|l|}{ Sex } \\
\hline Male & $46(38-54)$ & 0.84 (0.55-1.30), 0.434 & NS & $65(\mathrm{NR})$ & 0.98 (0.47-2.03), 0.951 & NS \\
\hline Female & $54(27-81)$ & & & NR & & \\
\hline \multicolumn{7}{|l|}{ Age } \\
\hline$<60$ years & $53(41-65)$ & 1.13 (0.72-1.77), 0.600 & NS & $\mathrm{NR}$ & $0.81(0.40-1.62), 0.544$ & NS \\
\hline$\geq 60$ years & $43(33-53)$ & & & $65(\mathrm{NR})$ & & \\
\hline \multicolumn{7}{|l|}{ Primary tumor } \\
\hline Rectum & $42(28-56)$ & 0.92 (0.61-1.39), 0.691 & NS & $65(\mathrm{NR})$ & 0.74 (0.37-1.49), 0.397 & NS \\
\hline Colon & $51(36-66)$ & & & NR & & \\
\hline
\end{tabular}


TABLE 3 continued

\begin{tabular}{|c|c|c|c|c|c|c|}
\hline \multirow[t]{2}{*}{ Characteristic } & \multicolumn{3}{|c|}{ Without chemotherapy } & \multicolumn{3}{|c|}{ With chemotherapy } \\
\hline & $\begin{array}{l}\text { Median survival } \\
(95 \% \mathrm{CI})\end{array}$ & $\begin{array}{l}\text { Univariate } \mathrm{HR} \\
(95 \% \mathrm{CI}), P \text { value }\end{array}$ & $\begin{array}{l}\text { Multivariate } \\
\text { HR (95\% CI) }\end{array}$ & $\begin{array}{l}\text { Median survival } \\
(95 \% \mathrm{CI})\end{array}$ & $\begin{array}{l}\text { Univariate } \mathrm{HR} \\
(95 \% \mathrm{CI}), P \text { value }\end{array}$ & $\begin{array}{l}\text { Multivariate } \\
\text { HR }(95 \% \text { CI) }\end{array}$ \\
\hline \multicolumn{7}{|c|}{$\mathrm{T}$ stage primary tumor } \\
\hline $\mathrm{T} 1-3$ & $51(40-62)$ & $1.72(0.86-3.43), 0.122$ & NS & NR & $2.84(1.08-7.49), 0.035$ & $2.84(1.08-7.59)$ \\
\hline $\mathrm{T} 4$ & $34(3-65)$ & & & $32(16-48)$ & & 0.035 \\
\hline \multicolumn{7}{|l|}{ Lymph node } \\
\hline Negative & $64(44-84)$ & $1.45(0.95-2.22), 0.084$ & NS & 65 (31-99) & $1.53(0.70-3.34), 0.287$ & NS \\
\hline Positive & $42(28-56)$ & & & NR & & \\
\hline \multicolumn{7}{|l|}{ Hepatic metastases } \\
\hline \multicolumn{7}{|l|}{ Time diagnosis } \\
\hline Metachronous & $54(41-67)$ & $1.18(0.77-1.82), 0.443$ & NS & 46 (NR) & $0.93(0.43-2.01), 0.851$ & NS \\
\hline Synchronous & $42(38-46)$ & & & NR & & \\
\hline \multicolumn{7}{|l|}{ No. of metastases } \\
\hline$\leq 3$ & $48(37-59)$ & $1.68(0.87-3.26), 0.123$ & NS & NR & $2.24(1.06-4.75), 0.036$ & NS \\
\hline$\geq 4$ & $32(14-50)$ & & & $43(27-59)$ & & \\
\hline \multicolumn{7}{|c|}{ Largest metastasis size } \\
\hline$<4$ & $46(37-55)$ & $1.05(0.69-1.62), 0.811$ & NS & $65(35-95)$ & $0.55(0.21-1.43), 0.220$ & NS \\
\hline$\geq 4$ & $48(27-69)$ & & & NR & & \\
\hline \multicolumn{7}{|c|}{ Tumor distribution } \\
\hline Unilobar & $51(39-63)$ & $1.11(0.71-1.74), 0.639$ & NS & NR & $2.13(1.06-4.29), 0.035$ & NS \\
\hline Bilobar & $42(29-55)$ & & & 45 (NR) & & \\
\hline \multicolumn{7}{|l|}{ CEA level } \\
\hline$<50$ & $51(41-61)$ & 1.37 (0.85-2.10), 0.208 & NS & $65(\mathrm{NR})$ & $0.49(0.12-2.07), 0.335$ & NS \\
\hline$\geq 50$ & $36(16-56)$ & & & NR & & \\
\hline \multicolumn{7}{|l|}{ Resection margin } \\
\hline R0 & $53(40-66)$ & $2.42(1.45-4.03), 0.001$ & $2.58(1.54-4.33)$ & $65(\mathrm{NR})$ & $0.78(0.27-2.24), 0.647$ & NS \\
\hline $\mathrm{R} 1$ & $30(13-47)$ & & $<0.001$ & NR & & \\
\hline
\end{tabular}

$N S$ not significant, $N R$ not reached

represents the predominant site of cancer relapse after curative resection of CRLM, with up to $50 \%$ in the first 2 years. $^{33,34}$ Thus, there is a rationale for perioperative chemotherapy, although controversy remains. The role of perioperative chemotherapy in the case of resectable metastases was investigated in one randomized controlled trial, which compared perioperative chemotherapy with surgery alone. ${ }^{35}$ It remains unknown whether the positive effects reported in the treatment arm were related to neoadjuvant chemotherapy and/or to adjuvant chemotherapy. A study by Adam et al. answered the pending question whether perioperative chemotherapy is really beneficial in patients developing solitary metastases. ${ }^{36}$ Although preoperative chemotherapy does not seem to benefit the outcome of patients with solitary metachronous CRLM, postoperative chemotherapy is associated with better OS and DFS, mainly when the tumor diameter exceeds $5 \mathrm{~cm} .{ }^{36}$ In four randomized trials, liver resection was followed by adjuvant systemic chemotherapy or observation. ${ }^{37-40}$ None of the studies displayed an OS or DFS benefit. Mitry et al. performed a meta-analysis from two trials above. ${ }^{41}$ In multivariate analysis, adjuvant chemotherapy was independently associated with progression-free survival. Although there are strong theoretical arguments in favor of adjuvant systemic chemotherapy after resection of liver metastases, the evidence to suggest an improvement in survival after this regime is still lacking. ${ }^{42}$

Hou et al. found no difference in OS between R0 and $\mathrm{R} 1$ resections in patients with colorectal metastases $(P=0.0776)$. In their study, patients did not receive neoadjuvant chemotherapy but were administered adjuvant hepatic arterial chemotherapy after resection. Furthermore, they used additional cryotherapy after resection of CRLM. ${ }^{43}$ Yan et al. also suggested that cryotherapy is useful after resection of CRLM; they found no difference between close or involved surgical margins $(P=0.084){ }^{44}$ It is possible that in case of additional cryotherapy, the micrometastases that were 
not resected were eliminated by the edge cryotherapy because edge cryotherapy can provide an area of tumor eradication of up to another $1 \mathrm{~cm}$.

To explain these results, it is necessary to consider several characteristics of CRLM. One feature is micrometastases. $^{45-47}$ Some found that approximately $95 \%$ of intrahepatic micrometastases are found in the close zone of $<1 \mathrm{~cm}$ from the gross hepatic tumor, and therefore suggested that a resection margin of $1 \mathrm{~cm}$ should remain the goal for resection of CRLM. ${ }^{47}$ Others collected positive samples only within $4 \mathrm{~mm}$ of the tumor border. ${ }^{46,48}$ Nanko et al. state that the bigger the macrometastases, the more micrometastases, and the further away they are located. ${ }^{45}$ Yamamoto et al. could not demonstrate a relationship between distance and tumor size. ${ }^{49}$ Because there are several methods for detection of micrometastases, not all investigators report similar results on incidence. For example, when genetic analysis is used, only $2 \%$ of micrometastases were detected, whereas with basic histopathology, a detection rate of 56\% was achieved, and with immunohistochemical staining, the detection rate is $58 \% .^{45-47}$ These differences in detection method might explain why micrometastases distribution is very different in these studies.

It is widely accepted that neoadjuvant chemotherapy can decrease the size of metastases. But how neoadjuvant chemotherapy decreases the size of CRLM remains unclear. $\mathrm{Ng}$ et al. showed that cell death is randomly distributed, probably as a result of variations in chemosensitivity of tumor cells, and that tumor shrinkage occurs in a concentric manner. ${ }^{48}$ They also found that viable tumor cells were more frequent in the periphery of metastases, whether or not they were treated with chemotherapy. Mentha et al. reported similar results with the finding of a dangerous "halo" (regrowth occurring at the periphery rather than in the center of the metastasis when chemotherapy is interrupted). ${ }^{50}$ They state that the surgeon should aim for a wider resection margin than $1 \mathrm{~mm}$. Nevertheless, Klinger et al. rarely observed a dangerous halo. ${ }^{51}$ In their study, the tumor glands were located mostly in the periphery of the metastases but were still covered by a layer of fibrotic tissue, and therefore parenchymal transection could be performed within the new borders (after response to chemotherapy) without increasing the incidence of local recurrence. ${ }^{51}$ This phenomenon supports our results.

Neoadjuvant chemotherapy is able to shrink the tumor, as described before. We believe that this is a concentric rather than a scattering response, as sometimes seen in primary tumors; perhaps micrometastases in the periphery of the tumor were destroyed. ${ }^{52}$ This could explain why recurrence was similar in R0 and R1 resection in patients who received neoadjuvant chemotherapy. This also explains the successful downsizing of formerly unresectable metastases into resectable metastases with almost the same outcome in primary resectable cases. A concern of neoadjuvant chemotherapy might be the disappearance of smaller lesions after several lines of chemotherapy and the difficulty identifying these lesions during surgery. The need to resect all tumors observed on the prechemotherapy imaging was demonstrated previously. ${ }^{53,54}$ Another concern of chemotherapy is additional complications after liver resection. However, it is known from the literature that if limited cycles of chemotherapy are provided in the neoadjuvant setting, the morbidity or mortality of liver surgery is not increased. ${ }^{55,56}$ Therefore, we administer to our patients $<6$ cycles of chemotherapy and evaluate after 2-3 cycles.

Several authors state that the width of the negative margins (R0) does not show a correlation with survival. ${ }^{21,22,25,57}$ In all these studies, a considerable proportion of the patients received neoadjuvant chemotherapy and/or adjuvant chemotherapy. In our study, we demonstrated in both univariate and multivariate analyses that the 5-year OS for patients without neoadjuvant chemotherapy showed a marked difference between R0 and R1 resection. Others proposed that margin widths of 2 and $5 \mathrm{~mm}$, respectively, were acceptable and led to similar outcomes compared with $1-\mathrm{cm}$ margin resection. ${ }^{28,29,46} \mathrm{We}$ also analyzed whether margin width $\leq 2 \mathrm{~mm}$ or $>2 \mathrm{~mm}$ influenced survival. This proved to be the case $(P=0.04)$ in patients who had a R0 resection without neoadjuvant chemotherapy. In patients with neoadjuvant chemotherapy, this phenomenon could not be demonstrated $(P=0.564)$. A similar trend was found if a tumor-free margins of $0-5 \mathrm{~mm}$ versus $>5 \mathrm{~mm}$ was chosen. It seems that the width of the resection margin still correlates with survival, but this only applies to patients who did not receive chemotherapy. This supports our hypothesis that neoadjuvant chemotherapy is able to destroy micrometastases in the periphery, and that in patients, the same survival rate, regardless of the width of the negative margins, is achieved. Therefore, data should be revised, and patients who did and did not receive chemotherapy should be investigated separately.

Yamamoto et al. described another feature of some CRLM. ${ }^{49}$ They found that one third of their patients have a thick fibrous pseudocapsule and suggested that a generous surgical margin is not required for resection. Later, the same group reported on a larger cohort and demonstrated that a thicker pseudocapsule leads to fewer R1/R2 resections. ${ }^{58}$ Although not significant, there was some relation between the presence of a pseudocapsule and the ability to achieve complete resection. Pseudocapsule formation was not available in our data set, so we could not compare this in the different chemotherapy groups. 
In conclusion, in the present series, the DFS and OS in patients with neoadjuvant chemotherapy is similar for patients with either $\mathrm{R} 0$ or $\mathrm{R} 1$ resection.

OPEN ACCESS This article is distributed under the terms of the Creative Commons Attribution Noncommercial License which permits any noncommercial use, distribution, and reproduction in any medium, provided the original author(s) and source are credited.

\section{REFERENCES}

1. Bengmark S, Hafstrom L. The natural history of primary and secondary malignant tumors of the liver. I. The prognosis for patients with hepatic metastases from colonic and rectal carcinoma by laparotomy. Cancer. 1969;23:198-202.

2. Simmonds PC. Palliative chemotherapy for advanced colorectal cancer: systematic review and meta-analysis. Colorectal Cancer Collaborative Group. BMJ. 2000;321(7260):531-5.

3. Seymour MT, Stenning SP, Cassidy J. Attitudes and practice in the management of metastatic colorectal cancer in Britain. Colorectal Cancer Working Party of the UK Medical Research Council. Clin Oncol (R Coll Radiol). 1997;9:248-51.

4. Adam R. Chemotherapy and surgery: new perspectives on the treatment of unresectable liver metastases. Ann Oncol. 2003; 14(Suppl. 2):ii13-6.

5. Scheele J, Stangl R, Altendorf-Hofmann A. Hepatic metastases from colorectal carcinoma: impact of surgical resection on the natural history. Br J Surg. 1990;77:1241-6.

6. Scheele J, Altendorf-Hofmann A. Resection of colorectal liver metastases. Langenbecks Arch Surg. 1999;384:313-27.

7. Adam R, Avisar E, Ariche A, et al. Five-year survival following hepatic resection after neoadjuvant therapy for nonresectable colorectal. Ann Surg Oncol. 2001;8:347-53.

8. Nordlinger B, Guiguet M, Vaillant JC, et al. Surgical resection of colorectal carcinoma metastases to the liver. A prognostic scoring system to improve case selection, based on 1568 patients. Association Francaise de Chirurgie. Cancer. 1996;77: 1254-62.

9. Giacchetti S, Itzhaki M, Gruia G, et al. Long-term survival of patients with unresectable colorectal cancer liver metastases following infusional chemotherapy with 5-fluorouracil, leucovorin, oxaliplatin and surgery. Ann Oncol. 1999;10:663-9.

10. Nikfarjam M, Shereef S, Kimchi ET, et al. Survival outcomes of patients with colorectal liver metastases following hepatic resection or ablation in the era of effective chemotherapy. Ann Surg Oncol. 2009;16:1860-7.

11. Fong Y, Fortner J, Sun RL, et al. Clinical score for predicting recurrence after hepatic resection for metastatic colorectal cancer: analysis of 1001 consecutive cases. Ann Surg. 1999;230:309-18.

12. Iwatsuki S, Dvorchik I, Madariaga JR, et al. Hepatic resection for metastatic colorectal adenocarcinoma: a proposal of a prognostic scoring system. J Am Coll Surg. 1999;189:291-9.

13. Nagashima I, Takada T, Nagawa H, et al. Proposal of a new and simple staging system of colorectal liver metastasis. World $J$ Gastroenterol. 2006;12:6961-5.

14. Konopke R, Kersting S, Distler M, et al. Prognostic factors and evaluation of a clinical score for predicting survival after resection of colorectal liver metastases. Liver Int. 2009;29:89-102.

15. Rees M, Tekkis PP, Welsh FK, et al. Evaluation of long-term survival after hepatic resection for metastatic colorectal cancer: a multifactorial model of 929 patients. Ann Surg. 2008;247:125-35.

16. Lise M, Bacchetti S, Da Pian P, et al. Patterns of recurrence after resection of colorectal liver metastases: prediction by models of outcome analysis. World J Surg. 2001;25:638-44.
17. Schindl M, Wigmore SJ, Currie EJ, et al. Prognostic scoring in colorectal cancer liver metastases: development and validation. Arch Surg. 2005;140:183-9.

18. Cady B, Jenkins RL, Steele GD, Jr., et al. Surgical margin in hepatic resection for colorectal metastasis: a critical and improvable determinant of outcome. Ann Surg. 1998;227:566-71.

19. Scheele J, Stang R, Altendorf-Hofmann A, et al. Resection of colorectal liver metastases. World J Surg. 1995;19:59-71.

20. Shirabe K, Takenaka K, Gion T, et al. Analysis of prognostic risk factors in hepatic resection for metastatic colorectal carcinoma with special reference to the surgical margin. Br J Surg. 1997; 84:1077-80.

21. Pawlik TM, Scoggins CR, Zorzi D, et al. Effect of surgical margin status on survival and site of recurrence after hepatic resection for colorectal metastases. Ann Surg. 2005;241:715-22.

22. Figueras J, Burdio F, Ramos E, et al. Effect of subcentimeter nonpositive resection margin on hepatic recurrence in patients undergoing hepatectomy for colorectal liver metastases. Evidences from 663 liver resections. Ann Oncol. 2007;18:1190-5.

23. Elias D, Cavalcanti A, Sabourin JC, et al. Resection of liver metastases from colorectal cancer: the real impact of the surgical margin. Eur J Surg Oncol. 1998;24:174-9.

24. Elias D, Cavalcanti A, Sabourin JC, et al. Results of 136 curative hepatectomies with a safety margin of less than $10 \mathrm{~mm}$ for colorectal metastases. J Surg Oncol. 1998;69:88-93.

25. Bodingbauer M, Tamandl D, Schmid K, et al. Size of surgical margin does not influence recurrence rates after curative liver resection for colorectal cancer liver metastases. Br J Surg. 2007; 94:1133-8.

26. de Haas RJ, Wicherts DA, Flores E, et al. R1 resection by necessity for colorectal liver metastases: is it still a contraindication to surgery? Ann Surg. 2008;248:626-37.

27. Choti MA, Sitzmann JV, Tiburi MF, et al. Trends in long-term survival following liver resection for hepatic colorectal metastases. Ann Surg. 2002;235:759-66.

28. Nuzzo G, Giuliante F, Ardito F, et al. Influence of surgical margin on type of recurrence after liver resection for colorectal metastases: a single-center experience. Surgery. 2008;143: 384-93.

29. Poultsides GA, Schulick RD, Pawlik TM. Hepatic resection for colorectal metastases: the impact of surgical margin status on outcome. HPB (Oxford). 2010;12:43-9.

30. Cady B, McDermott WV. Major hepatic resection for metachronous metastases from colon cancer. Ann Surg. 1985;201:204-9.

31. Ekberg H, Tranberg KG, Andersson R, et al. Determinants of survival in liver resection for colorectal secondaries. Br J Surg. 1986;73:727-31.

32. Pawlik TM, Vauthey JN. Surgical margins during hepatic surgery for colorectal liver metastases: complete resection not millimeters defines outcome. Ann Surg Oncol. 2008;15:677-9.

33. Fong Y, Cohen AM, Fortner JG, et al. Liver resection for colorectal metastases. J Clin Oncol. 1997;15:938-46.

34. Petrelli NJ. Perioperative or adjuvant therapy for resectable colorectal hepatic metastases. J Clin Oncol. 2008;26:4862-3.

35. Nordlinger B, Sorbye H, Glimelius B, et al. Perioperative chemotherapy with FOLFOX4 and surgery versus surgery alone for resectable liver metastases from colorectal cancer (EORTC Intergroup trial 40983): a randomised controlled trial. Lancet. 2008;371(9617):1007-16.

36. Adam R, Bhangui P, Poston G, et al. Is perioperative chemotherapy useful for solitary, metachronous, colorectal liver metastases? Ann Surg. 2010;252:774-87.

37. Langer B, Bleiberg H, Labianca R, Shepherd L, Nitti D, Marsoni S, Tu D, Sargeant A-M, Fields A. Fluorouracil (FU) plus 1-leucovorin (1-LV) versus observation after potentially curative resection of liver or lung metastases from colorectal cancer 
(CRC): results of the ENG (EORTC/NCIC CTG/GIVIO) randomized trial. Proc Am Soc Clin Oncol. 2002;21:592.

38. O'Connell MJ, Adson MA, Schutt AJ, et al. Clinical trial of adjuvant chemotherapy after surgical resection of colorectal cancer metastatic to the liver. Mayo Clin Proc. 1985;60:517-20.

39. Lopez-Ladron A, Salvador AJ, Bernabe R, Bernardos A, Arriola E, Serrano J, Reina JJ, Gomez MA, Barneto I, Moreno-Nogueira JA Observation versus postoperative chemotherapy after resection of liver metastases in patients with advanced colorectal cancer. Proc Am Soc Clin Oncol. 2003;22:1497.

40. Portier G, Elias D, Bouche O, et al. Multicenter randomized trial of adjuvant fluorouracil and folinic acid compared with surgery alone after resection of colorectal liver metastases: FFCD ACHBTH AURC 9002 trial. J Clin Oncol. 2006;24:4976-82.

41. Mitry E, Fields AL, Bleiberg H, et al. Adjuvant chemotherapy after potentially curative resection of metastases from colorectal cancer: a pooled analysis of two randomized trials. J Clin Oncol. 2008;26:4906-11.

42. Taylor I. Adjuvant chemotherapy after resection of liver metastases from colorectal cancer. Eur J Cancer. 2008;44:1198-201.

43. Hou RM, Chu F, Zhao J, et al. The effects of surgical margin and edge cryotherapy after liver resection for colorectal cancer metastases. HPB (Oxford). 2007;9:201-7.

44. Yan TD, Padang R, Xia H, et al. Management of involved or close resection margins in 120 patients with colorectal liver metastases: edge cryotherapy can achieve long-term survival. Am J Surg. 2006;191:735-42.

45. Nanko M, Shimada H, Yamaoka H, et al. Micrometastatic colorectal cancer lesions in the liver. Surg Today. 1998;28:707-13.

46. Kokudo N, Miki Y, Sugai S, et al. Genetic and histological assessment of surgical margins in resected liver metastases from colorectal carcinoma: minimum surgical margins for successful resection. Arch Surg. 2002;137:833-40.

47. Wakai T, Shirai Y, Sakata J, et al. Appraisal of $1 \mathrm{~cm}$ hepatectomy margins for intrahepatic micrometastases in patients with colorectal carcinoma liver metastasis. Ann Surg Oncol. 2008;15: 2472-81.

48. Ng JK, Urbanski SJ, Mangat N, et al. Colorectal liver metastases contract centripetally with a response to chemotherapy: a histomorphologic study. Cancer. 2008;112:362-71.
49. Yamamoto J, Sugihara K, Kosuge T, et al. Pathologic support for limited hepatectomy in the treatment of liver metastases from colorectal cancer. Ann Surg. 1995;221:74-8.

50. Mentha G, Majno PE, Andres A, et al. Neoadjuvant chemotherapy and resection of advanced synchronous liver metastases before treatment of the colorectal primary. Br J Surg. 2006;93: $872-8$.

51. Klinger M, Tamandl D, Eipeldauer S, et al. Bevacizumab improves pathological response of colorectal cancer liver metastases treated with XELOX/FOLFOX. Ann Surg Oncol. 2010;17:2059-65.

52. Burger JW, de Graaf EJ, Doornebosch PG, et al. Local excision of rectal cancer after chemoradiation: feasibility depends on the primary stage. Int J Colorectal Dis. 2010;25:1141-2.

53. Brouquet A, Abdalla EK, Kopetz S, et al. High survival rate after two-stage resection of advanced colorectal liver metastases: response-based selection and complete resection define outcome. J Clin Oncol. 2011;29:1083-90.

54. Benoist S, Brouquet A, Penna C, et al. Complete response of colorectal liver metastases after chemotherapy: does it mean cure? J Clin Oncol. 2006;24:3939-45.

55. Karoui M, Penna C, Amin-Hashem M, et al. Influence of preoperative chemotherapy on the risk of major hepatectomy for colorectal liver metastases. Ann Surg. 2006;243:1-7.

56. Allen PJ, Kemeny N, Jarnagin W, et al. Importance of response to neoadjuvant chemotherapy in patients undergoing resection of synchronous colorectal liver metastases. J Gastrointest Surg. 2003;7:109-15; discussion 116-7.

57. Hamady ZZ, Cameron IC, Wyatt $\mathrm{J}$, et al. Resection margin in patients undergoing hepatectomy for colorectal liver metastasis: a critical appraisal of the $1 \mathrm{~cm}$ rule. Eur J Surg Oncol. 2006;32: 557-63.

58. Okano K, Yamamoto J, Kosuge T, et al. Fibrous pseudocapsule of metastatic liver tumors from colorectal carcinoma. Clinicopathologic study of 152 first resection cases. Cancer. 2000;89: 267-75. 